\title{
Effects of various concentrations of gonadotropins and $17 \beta$ estradiol on the in vitro maturation of cattle oocytes selected using brilliant cresyl blue staining
}

\author{
K.P.M. Lekola ${ }^{1,3}$, J.W. Ng'ambi ${ }^{3}$, M. Nkadimeng ${ }^{1}$, M.L. Mphaphathi ${ }^{1}$ \\ \& T.L. Nedambale ${ }^{1,2 \#}$ \\ ${ }^{1}$ Agricultural Research Council, Animal Production Institute, Germplasm Conservation and Reproductive \\ Biotechnologies, Private Bag X2, Irene, 0062, South Africa \\ ${ }^{2}$ Tshwane University of Technology, Faculty of Science, Department of Animal Science, Private Bag X680, Pretoria, \\ 0001, South Africa \\ ${ }^{3}$ University of Limpopo, Department of Animal Production and Agricultural Economics, School of Agriculture and \\ Environmental Science, Faculty of Science and Agriculture, Private Bag X1106, Sovenga 0727, South Africa
}

(Received 8 May 2015; Accepted 2 August 2016; First published online 30 September 2016)

\begin{abstract}
Copyright resides with the authors in terms of the Creative Commons Attribution 2.5 South African Licence.
See: http://creativecommons.org/licenses/by/2.5/za

Condition of use: The user may copy, distribute, transmit and adapt the work, but must recognise the authors and the South African Journal of Animal Science.
\end{abstract}

\begin{abstract}
The objective of this study was to determine the in vitro maturation rate of cattle oocytes selected with brilliant cresyl blue (BCB) stain, in tissue culture medium 199 (TCM 199) supplemented with various concentrations of hormones. Oocytes were retrieved from abattoir-derived ovaries by aspiration. Oocytes were then exposed to $26 \mu \mathrm{M} \mathrm{BCB}$ stain, and classified according to the colour of their cytoplasm: BCB+ (oocytes with blue cytoplasm) and BCB- (unstained oocytes). The BCB selected and the non-selected immature oocytes were randomly allocated into TCM $199+10 \%$ foetal bovine serum (FBS) maturation media supplemented with three concentrations of hormones as treatments $(T)$. The T1 group was matured in the presence of $0.5 \mu \mathrm{g}$ follicle stimulating hormone $(\mathrm{FSH}) / \mathrm{mL}, 5 \mathrm{mg}$ luteinising hormone (LH)/mL and $2 \mu \mathrm{g}$ estradiol $\left(E_{2}\right) / \mathrm{mL}$. The T2 group was matured in $1 \mu \mathrm{g} \mathrm{FSH}, 6 \mathrm{mg} \mathrm{LH}$ and $2.5 \mu \mathrm{g} \mathrm{E}_{2} / \mathrm{mL}$. The T3 group was matured in $1.5 \mu \mathrm{g} \mathrm{FSH}, 7 \mathrm{mg} \mathrm{LH}$ and $4.5 \mu \mathrm{g} \mathrm{E} / \mathrm{mL}$. The maturation rate of oocytes was determined by the protrusion of the first polar bodies $24 \mathrm{~h}$ after maturation. Data were analysed by ANOVA using SAS. Treatment 2 yielded higher maturation rates for with $\mathrm{BCB}+(30.5 \%)$ and without $\mathrm{BCB}(35 \%)$ oocytes, with $\mathrm{T} 1$ giving a lower maturation rate for $\mathrm{BCB}+(10.7 \%)$ and without $\mathrm{BCB}(9.7 \%)$ oocytes. However, $\mathrm{BCB}-$ oocytes had lower polar body extrusion $(0.7 \%, 1 \%$ and $2.7 \%)$ for T1, T2 and T3, respectively. In conclusion, immature oocytes that were exposed to BCB+ and cultured in TCM 199 supplemented with $10 \% \mathrm{FBS}, 1 \mu \mathrm{g}$ $\mathrm{FSH}, 6 \mathrm{mg} \mathrm{LH}$ and $2.5 \mu \mathrm{g} \mathrm{E} / \mathrm{mL}$ had a higher number of matured oocytes (extrusion of first polar body), similar to those that were not exposed to $\mathrm{BCB}$ (no BCB). Oocyte selection with BCB staining was a useful test for classifying good-quality cattle oocytes.
\end{abstract}

Keywords: Cattle, $\mathrm{E}_{2}, \mathrm{FSH}$, in vitro maturation, polar bodies, ovaries

"Corresponding author: nedambaletl@tut.ac.za

\section{Introduction}

Livestock plays a vital role in the agricultural and rural economies of developing countries (Rosengrant et al., 2002). Cattle, together with small ruminants, account for the largest part of the economies in these countries in terms of milk, meat, hides and wool production (Francis, 1988). However, cattle productivity is low, leading to economic losses in the livestock industry. Poor productivity can be observed when a cow does not become pregnant during a defined breeding season (Chakravarthi \& Balaji, 2010). Such matters can be resolved with assisted reproduction technologies such as oestrus synchronization, embryo transfer, artificial insemination and in vitro embryo production (IVEP), which are important in maximizing production (Rodriguez-Martinez, 2012).

The IVEP technique is one of the assisted reproduction technologies that have great potential for speeding up genetic improvement in cattle (Baldassarre \& Karatzas, 2004). The IVEP process encompasses three steps: recovering oocytes from cattle ovaries and maturing them in vitro (IVM), in vitro fertilization (IVF), and in vitro culture (IVC) of the zygotes to the blastocyst stage (Nedambale et al., 2004), with IVM being the first and the most critical step in a successful IVEP. An oocyte is considered morphologically mature when the first polar body is extruded and the oocyte is arrested at the metaphase of the second 
meiotic division (Heleil, 2010). During the gametogenesis process, fully grown oocytes generally arrest at prophase I (germinal vesicle stage) of meiosis. Mostly meiosis is reinitiated upon hormonal stimulation and results first in germinal vesicle breakdown and extrusion of the polar body, with a secondary arrest usually occurring at metaphase I (MI) or metaphase II (MII) of meiotic maturation, which is later released by fertilization (Pfeifer et al., 2008). In some mammals, progression from prophase I to MII is initially promoted by a surge in progesterone or luteinising hormone (LH) levels (Jahn \& Sudhof, 1999). The ability of oocytes to undergo IVM and subsequent embryo development is influenced by maturation media and supplements (Farag et al., 2009). A chemically defined medium is considered important to address the exact effects of any supplement of interest in the medium on oocyte maturation or embryo development (Motlagh et al., 2008). The strategic way of increasing the developmental ability of in vitro matured oocytes is by supplementing maturation with gonadotropic hormones and growth hormones (De Lima et al., 2010). Kojima et al. (2003) observed that the hormones that are commonly used in IVM are LH, follicle-stimulating hormone (FSH) and estradiol $\left(\mathrm{E}_{2}\right)$. According to Yamashita et al. (2011), the preovulatory LH surge is vital for cumulus cell expansion, which is often used as an indicator of oocyte maturation. Izadyar et al. (1997) observed that the presence of growth hormones $(\mathrm{GH})$ during IVM accelerates the kinetics of meiosis, increases cumulus cell expansion, and improves cytoplasmic maturation. Growth hormones also stimulate nuclear maturation in vitro in rats (Apa et al., 1994) and pigs (Hagen \& Graboski, 1990). The gonadotropins enhance the development and maturity of oocytes in vitro (Ferre et al., 2002).

The quality of oocytes can be determined by the exposure to BCB stain. BCB is a non-toxic stain, which can detect the activity of an enzyme known as glucose-6-phosphate dehydrogenase (Catala et al., 2011). Young growing oocytes are considered incompetent, whereas grown oocytes are considered competent (Su et al., 2012). Protocols for cattle in vitro embryo production are being used in several countries, but for various reasons (such as environmental differences, types of breeds and laboratory to laboratory differences) these protocols may not be efficient locally in South Africa or in the laboratory where the study was carried out. The objective of this study was to determine the in vitro maturation rate of cattle oocytes selected with brilliant cresyl blue (BCB) stain cultured in tissue culture medium 199 (TCM 199) supplemented with various concentrations of hormones.

\section{Materials and Methods}

All chemicals were purchased from Sigma Co. (St. Louis, Mo, USA), unless otherwise stated.

Ovaries from cows were collected from an abattoir (Morgan, Springs, RSA) and were transported to the laboratory within $2-3 \mathrm{~h}$ in a $37^{\circ} \mathrm{C}$ buffered saline. On arrival, the temperature was checked and ovaries were washed in a pre-warmed saline at $37^{\circ} \mathrm{C}$. Oocytes from follicles of $3-7 \mathrm{~mm}$ in diameter were recovered using an aspiration method with a sterilized 18-gauge needle and a $10 \mathrm{~mL}$ syringe. The recovered follicular fluid was mixed with modified dulbeco phosphate buffered saline (mDPBS), modified by the addition of $1 \%$ polyvinyl alcohol and supplemented with $10 \%$ antibiotic antimycotic solution. The mixture was left for 10 minutes for a pellet to settle. The oocytes were then searched under a stereo-microscope. The recovered oocytes were washed three times in mDPBS and in tissue culture medium (M199) plus $10 \%$ foetal bovine serum (FBS). A total number of 966 oocytes were exposed to $26 \mu \mathrm{M}$ commercial BCB stain for 90 min at 39 ${ }^{\circ} \mathrm{C}$ with $5 \% \mathrm{CO}_{2}$ (the manufacturer's protocol for $\mathrm{BCB}$ staining was followed), while 700 oocytes were not exposed to the BCB stain. The oocytes exposed to the BCB stain were then grouped according to the colour of their cytoplasm: BCB+ (oocytes with blue cytoplasm) and BCB- (oocytes with colourless cytoplasm). The oocytes that were exposed to $\mathrm{BCB}$ ( $\mathrm{BCB}+$ and $\mathrm{BCB}-$ ) and those that were not were randomly allocated to pre-warmed M199 + 10\% FBS, supplemented with three concentrations of hormones as treatments $(\mathrm{T})$, namely T1 $(0.5 \mu \mathrm{g} \mathrm{FSH} / \mathrm{mL}, 5 \mathrm{mg} \mathrm{LH} / \mathrm{mL}$ and $2 \mu \mathrm{g} \mathrm{E} / 2 / \mathrm{mL})$ as the control; T2 $(1 \mu \mathrm{g} \mathrm{FSH} / \mathrm{mL}, 6 \mathrm{mg} \mathrm{LH} / \mathrm{mL}$ and $2.5 \mu \mathrm{g} \mathrm{E} / 2 \mathrm{~mL})$; and T3 $\left(1.5 \mu \mathrm{g} \mathrm{FSH} / \mathrm{mL}, 7 \mathrm{mg} \mathrm{LH} / \mathrm{mL}\right.$ and $\left.4.5 \mu \mathrm{g} \mathrm{E}_{2} / \mathrm{mL}\right)$. Each treatment was replicated four times. The oocytes were then incubated for $24 \mathrm{~h}$ at $39{ }^{\circ} \mathrm{C}$ with $5 \% \mathrm{CO}_{2}$. Following incubation, cumulus cells were totally removed by vortexing, and the maturation rate was observed by detecting the first polar body with the micro-manipulation microscope using the Oosight imaging system, USA.

\section{Results}

The results of the effects of the hormonal supplementations on the in vitro maturation of cow oocytes are presented in Table 1. The means of polar body (Figure 2) extrusions of oocytes that were matured in the M199 medium supplemented with $1 \mu \mathrm{g} \mathrm{FSH}, 6 \mathrm{mg} \mathrm{LH}$ and $2.5 \mu \mathrm{g} \mathrm{E} / \mathrm{mL}$ were found to be significantly higher $(P<0.05)$ than the medium supplemented with $1.5 \mu \mathrm{g} \mathrm{FSH}, 7 \mathrm{mg} \mathrm{LH}$ and $4.5 \mu \mathrm{g} \mathrm{E} / \mathrm{mL}$ and $0.5 \mu \mathrm{g} \mathrm{FSH}, 5$ $\mathrm{mg} \mathrm{LH}$ and $2 \mu \mathrm{g} \mathrm{E} / \mathrm{mL}$. The BCB+ oocytes obtained significantly higher $(P<0.05)$ polar body extrusion in all the treatments than the $\mathrm{BCB}$ - oocytes. The oocytes that were not exposed to the $\mathrm{BCB}$ stain and the $\mathrm{BCB}+$ oocytes obtained similar $(P<0.05)$ numbers of polar body extrusions. 
Table 1 Effects of gonadotropin hormones (luteinising hormone and follicle-stimulating hormone) and estradiol on the in vitro maturation of cow oocytes selected by the brilliant cresyl blue (BCB) stain

\begin{tabular}{lcccc}
\hline $\begin{array}{l}\text { Oocyte } \\
\text { classification }\end{array}$ & Treatments & Oocytes $(\mathbf{n})$ & Polar body extrusions & No polar body \\
\hline \multirow{3}{*}{ No BCB } & & & & \\
& T1 & 234 & $16.6 \pm 4.11^{\mathrm{cd}}$ & $83.3 \pm 4.78^{\mathrm{a}}$ \\
& T2 & 232 & $60.3 \pm 10.39^{\mathrm{a}}$ & $39.5 \pm 4.69^{\mathrm{b}}$ \\
BCB- & T3 & 198 & $48.0 \pm 6.24^{\mathrm{bc}}$ & $52.0 \pm 1.90^{\mathrm{b}}$ \\
\cline { 2 - 4 } & T1 & 132 & $3.03 \pm 1.41^{\mathrm{d}}$ & $96.9 \pm 1.83^{\mathrm{ab}}$ \\
& T2 & 136 & $8.1 \pm 2.22^{\mathrm{d}}$ & $91.9 \pm 2.02^{\mathrm{ab}}$ \\
BCB+ & T3 & 135 & $2.2 \pm 0.95^{\mathrm{d}}$ & $97.8 \pm 3.62^{\mathrm{b}}$ \\
\hline & T1 & 190 & $22.6 \pm 5.73^{\mathrm{cd}}$ & $77.4 \pm 4.54^{\mathrm{ab}}$ \\
& T2 & 186 & $65.6 \pm 1.68^{\mathrm{ab}}$ & $34.4 \pm 3.64^{\mathrm{b}}$ \\
& T3 & 187 & $48.1 \pm 7.14^{\mathrm{bc}}$ & $51.8 \pm 1.50^{\mathrm{b}}$
\end{tabular}

a,b,c,d Values with different superscripts within column differ significantly at $P<0.05$.

T1: $0.5 \mu \mathrm{g} \mathrm{FSH} / \mathrm{mL}, 5 \mathrm{mg} \mathrm{LH} / \mathrm{mL}$ and $2 \mu \mathrm{g} \mathrm{E} / \mathrm{mL}$

T2: $1 \mu \mathrm{g} \mathrm{FSH} / \mathrm{mL}, 6 \mathrm{mg} \mathrm{LH} / \mathrm{mL}$ and $2.5 \mu \mathrm{g} \mathrm{E} / \mathrm{mL}$

T3: $1.5 \mu \mathrm{g} \mathrm{FSH} / \mathrm{mL}, 7 \mathrm{mg} \mathrm{LH} / \mathrm{mL}$ and $4.5 \mu \mathrm{g} \mathrm{E} / \mathrm{mL}$.

\section{Polar body extrusions}

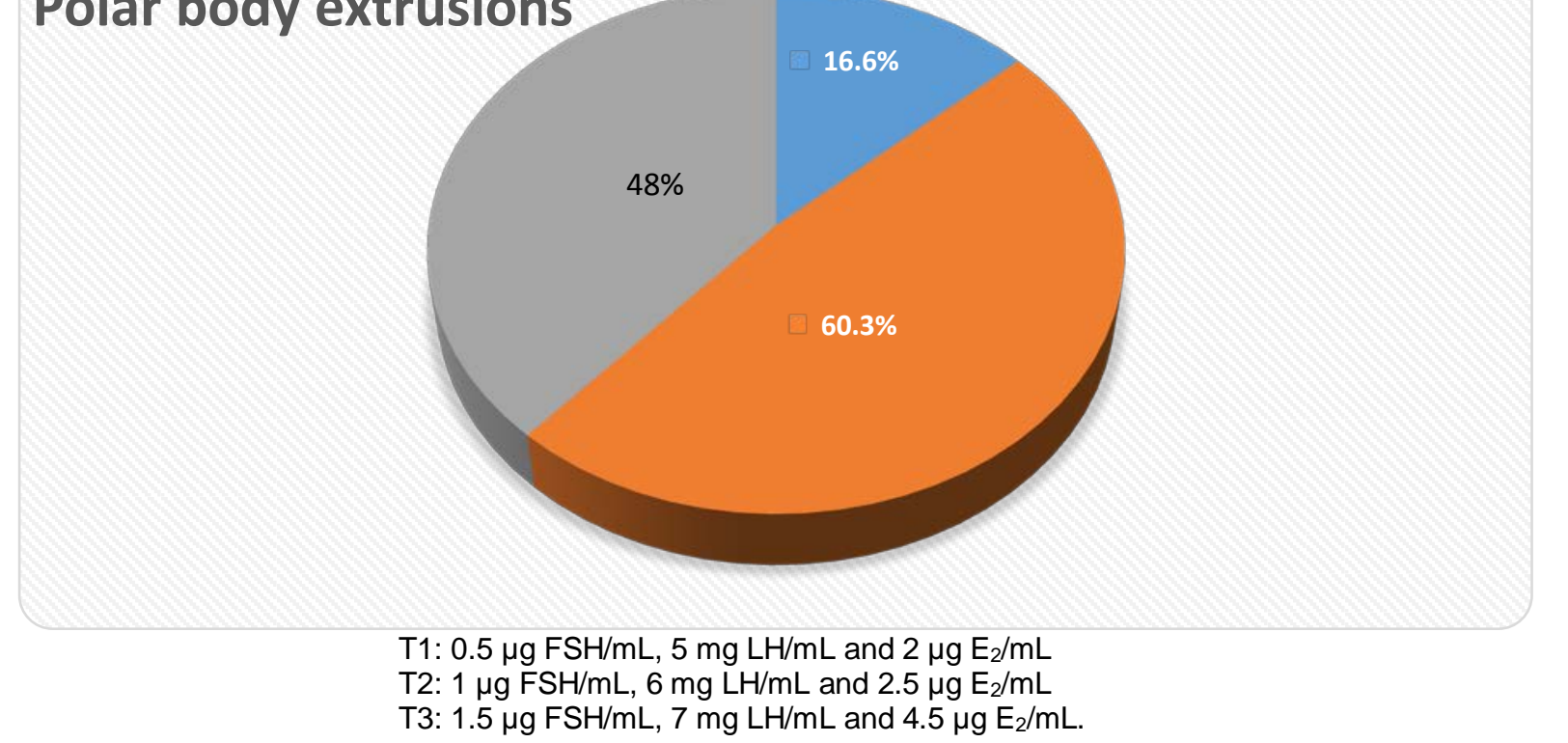

Figure 1 Effects of various hormonal concentrations on the maturation of cattle oocytes.

\section{Discussion}

In this study, the IVM medium [M199] supplemented with $1 \mu \mathrm{g} \mathrm{FSH} / \mathrm{mL}, 6 \mathrm{mg} \mathrm{LH} / \mathrm{mL}$ and $2.5 \mu \mathrm{g} \mathrm{E}_{2} / \mathrm{mL}$ yielded the highest number of oocytes that had extruded polar bodies for oocytes that were not exposed to BCB (60.3\%) and for BCB+ (65.6\%) oocytes. This study is comparable with that by Younis et al. (1991) in which they reported that the addition of the gonadotropic hormones ( $\mathrm{LH}$ and $\mathrm{FSH}$ ) to the maturation medium enhanced cumulus cell expansion of goat oocytes. Chen et al. (1994) suggested that FSH has a beneficial effect in the presence of FBS and enhances cumulus expansion of cattle oocytes. Some of the growing oocytes that did not absorb the stain under the same medium protruded polar bodies (8.1\%). This indicates that IVM medium supplemented with $1 \mu \mathrm{g} \mathrm{FSH} / \mathrm{mL}, 6 \mathrm{mg} \mathrm{LH} / \mathrm{mL}$ and $2.5 \mu \mathrm{g} \mathrm{E}_{2} / \mathrm{mL}$ is suitable for maturing 


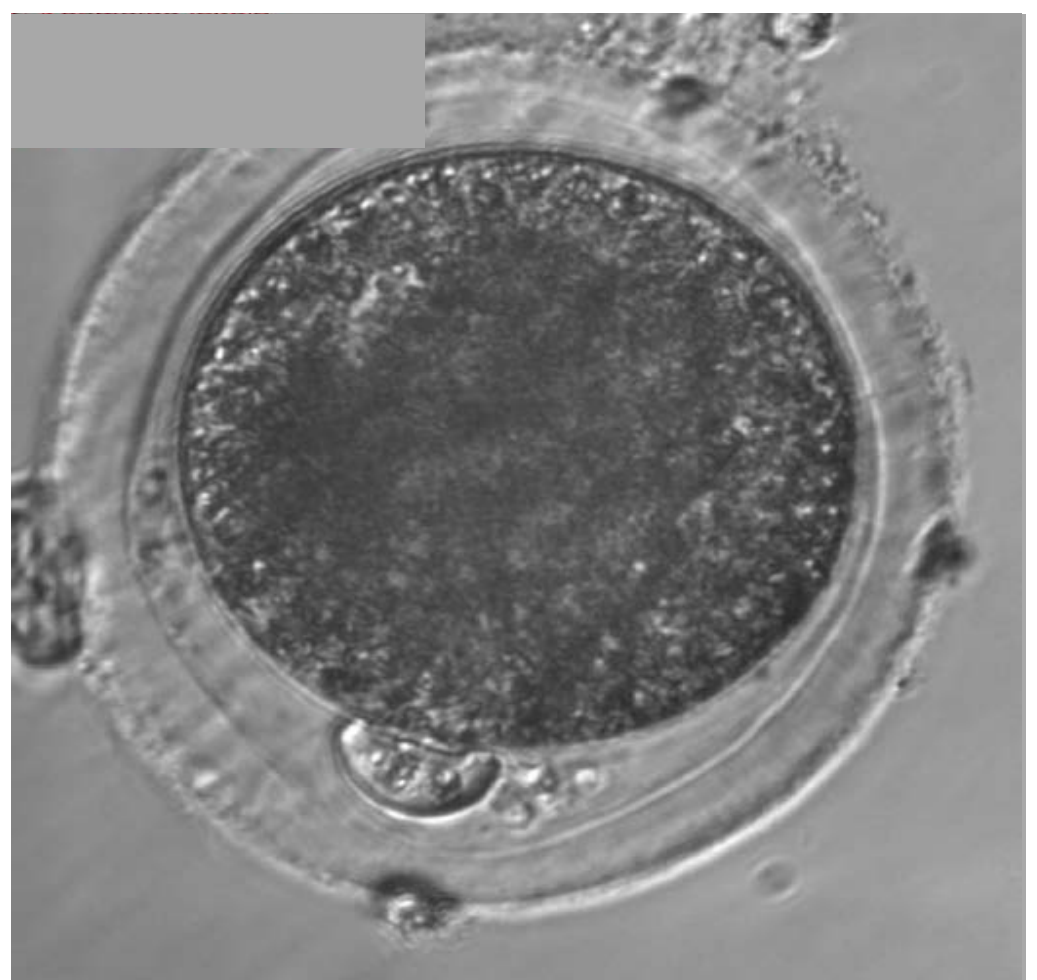

Figure 2 Matured oocyte with a polar body at 20X/0.45 RC2 magnification.

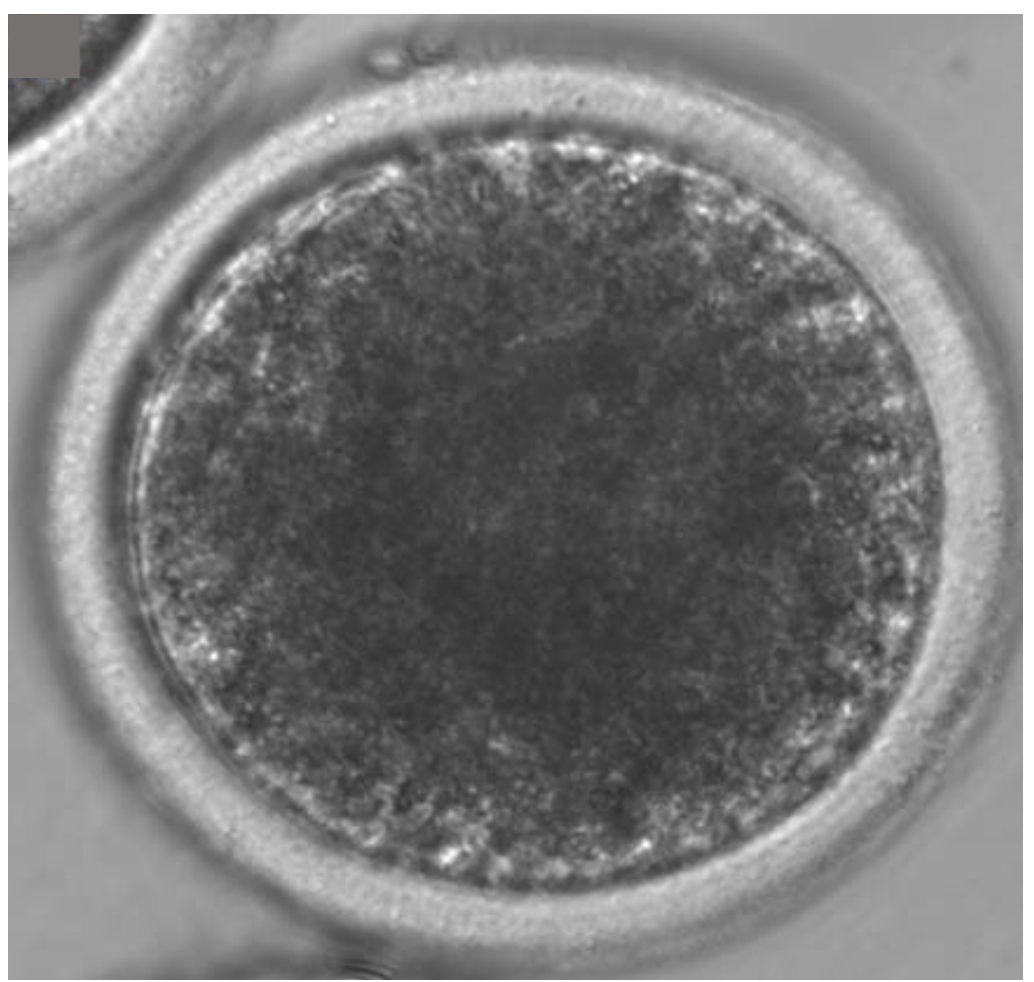

Figure 3 Immature oocyte without a polar body at 40X/0.60 RC3 magnification. 
cattle oocytes of South African origin and that even the oocytes from the atretic follicles could mature in vitro. The IVM medium with $0.5 \mu \mathrm{g} \mathrm{FSH} / \mathrm{mL}, 5 \mathrm{mg} \mathrm{LH} / \mathrm{mL}$ and $2 \mu \mathrm{g} \mathrm{E}_{2} / \mathrm{mL}$ obtained lower numbers of mature oocytes under the $\mathrm{BCB}$ selected oocytes as well as those that were not exposed to $\mathrm{BCB}$ (22.6, 16.6 and 3.03 , respectively). The standard concentration of $0.5 \mu \mathrm{g} \mathrm{FSH} / \mathrm{mL}, 5 \mathrm{mg} \mathrm{LH} / \mathrm{mL}$ and $2 \mu \mathrm{g} \mathrm{E} / 2 \mathrm{~mL}$ is widely used in IVM. The results of this study showed that BCB+ obtained more maturity than BCB- oocytes in the entire three maturation media whereby many oocytes in the BCB+ group (22.6, 65.6 and 48.1) obtained higher polar body extrusion compared with BCB-. Shourbagy et al. (2006) discovered that BCB+ oocytes have a larger cytoplasmic volume, are more likely to become fertilized compared to BCB- oocytes, contain a higher number of mitochondrial deoxyribose nucleic acid (mtDNA) copy number and have been linked to fertilization outcome in the buffalo and human oocytes. This study is comparable with the results obtained by Wang et al. (2012), in which it was observed that $\mathrm{BCB}+$ oocytes had significantly higher maturation rates than BCB- oocytes. Therefore, BCB+ oocytes have better developmental competency compared with the BCB- oocytes. The BCB stain has been proved to select good-quality oocytes that have better chances of survival and better embryonic developmental competency.

\section{Conclusion}

In conclusion, the BCB+ immature oocytes (Treatment 2) that were cultured in TCM 199 supplemented with $10 \% \mathrm{FBS}, 1 \mu \mathrm{g} \mathrm{FSH} / \mathrm{mL}, 6 \mathrm{mg} \mathrm{LH} / \mathrm{mL}$ and $2.5 \mu \mathrm{g} \mathrm{E}_{2} / \mathrm{mL}$ had higher in vitro maturation rate similarly to those in Treatment 2 without $\mathrm{BCB}$ treatment compared to other treatments. Thus it showed that culturing immature oocytes TCM 199 supplemented with 10\% FBS, $1 \mu \mathrm{g} \mathrm{FSH} / \mathrm{mL}, 6 \mathrm{mg} \mathrm{LH} / \mathrm{mL}$ and 2.5 $\mu \mathrm{g} E_{2} / \mathrm{mL}$ was a suitable protocol for cattle oocytes. Oocyte selection using BCB staining is a useful test for classifying good-quality cattle oocytes.

\section{Acknowledgements}

The study was supported by the Agriculture Research Council; Professional Development Programme Grant (3014KPM) and Technology Innovation Agency (TIA).

\section{Authors' Contributions}

KPML was involved in the experimental design, data collection, data analysis, data interpretation and manuscript writing. MLN was involved in assisting the data collection. MLM was involved in study design and data interpretation. JWN was involved in study design, data analysis, data interpretation and manuscript editing. The Research Team Manager, TLN, was involved in the study design and manuscript editing and principal investigator. All authors have read and approved the final manuscript.

\section{Conflict of Interest Declaration}

The authors declare that there is no conflict of interest.

\section{References}

Apa, R., Caruso, A., Andreani, G., Miceli, F., Lazzarin, N., Mastandrea, M., Ronsisville, E., Mancuso, S. \& Lanzone, A., 1994. Growth hormone stimulates androsterone synthesis by rat theca-interstitial cells. Mol. Cell Endocrinol. 118, 95-101.

Baldassarre, H. \& Karatzas, C.N., 2004. Advanced assisted reproduction technologies. ART in goats. Anim. Reprod. Sci. 82 (83), 255-266.

Catala, M.G., Izquierdo, D., Uzbekowa, S., Morato, R., Roura, M., Romaguera, R., Papillier, P. \& Paramio, M.P., 2011. Brilliant cresyl blue stain selects largest oocytes with high mitochondria activity, MPF activity and embryo development competence in prepubertal sheep. Reprod. 10, 0528.

Chakravarthi, V.P. \& Sri Balaji, N., 2010. Use of assisted reproductive technologies for livestock development. Vet. World 3, 238-240.

Chen, L., Russell, P.T. \& Larsen, W.J., 1994. Sequential effects of follicle-stimulating hormone and luteinizing hormone on mouse cumulus expansion in vitro. Biol. Reprod. 51, 290-295.

De Lima, A.S., Marques, G.M., Nascimento, A.B., Ortiz, M.E., Assumpcao, D. \& Visitin, J.A., 2010. Effect of hormonal supplementation periods and in vitro maturation media on developmental competence of pig oocytes. Acta Sci. Vet. 38, 407-413.

Farag, I.M., Girgis, S.M., Khalil, W.K.B., Hassan. N.H.A., Sakr, A.A.M., Allah, S.M.A. \& Ali, N.I., 2009. Effect of hormones, culture media and oocyte quality on in vitro maturation of Egyptian sheep oocytes. J. Appl. Biosci. 24, 1520-1534.

Ferre, L.B., Dalla, L.M., Medina, M. \& Brogliatti, G., 2002. In vitro embryo production and pregnancy rates from problem, pregnant and cyclic cows by tranvaginal ovum pick-up. Theriogenology $57,664$.

Francis, P.A., 1988. Ox draught power and agricultural transformation. Northern Zambia Agricultural Systems 27, 35-49.

Hagen, D.R. \& Graboski, R.A., 1990. Effect of porcine pituitary growth (pGH) on cytoplasmic maturation of porcine oocytes in vitro. J. Anim. Sci. $68,446$. 
Heleil, B., Kuzmina, T., Novikova, N., Torner, H. \& Alm, H., 2010. Effect of prolactin on development competence of cattle oocytes selected by brilliant cresyl blue staining. J. Reprod. Infertil. 1, 1-7.

Izadyar, F., Colenbrander, B. \& Bevers, M.M., 1997. Stimulatory effect of growth hormone on in vitro maturation of cattle oocytes is exerted through the cyclic adenosine $3^{\prime}, 5^{\prime}-$ monophosphate signalling pathway. Biol. Reprod. 57, 1484-1489.

Jahn, R. \& Sudhof, T.C., 1999. Membrane fusion and exocytosis. Annu. Rev. Biochem. 68, 863-911.

Kojima, F.N., Bergfeld, E.G.M., Wehrman, M.E., Cupp, A.S., Fike, K.E., Mariscal-Aguayo, D.V., Sanchez-Torres, T., Garcia-Winder, M., Clopton, D.T., Roberts, A.J. \& Kinder, J.K., 2003. Frequency of luteinizing hormone pulses in cattle influences duration of persistence of dominant ovarian follicles, follicular fluid concentrations of steroids, and activity of insulin-like growth factor binding proteins. Anim. Prod. Sci. 77, 187-211.

Motlagh, M.K., Shahneh, A.Z., Daliri, M., Kohram, H. \& Ghargozion, F., 2008. In vitro maturation of sheep oocytes in different concentration of mare serum. Afr. J. Biotechnol. 7, 3380-3382.

Nedambale, T.L., Dinnyes, A., Groen, W., Dobrinsky, J.R., Tian, X.C. \& Yang, X., 2004. Comparison on in vitro fertilized cattle embryos cultured in KSOM or SOF and cryopreserved by slow freezing or vitrification. Theriogenology 63 , 437-449.

Pfeifer, L.F.M., Schneider, A. \& Correa, M., 2008. Factors that affect in vitro production of cattle embryos. Rev. Colomb. Cienc. Pec. 21, 109-120.

Rodriguez-Martine, Z.H., 2012. Assisted reproductive techniques for cattle breeding in developing countries: A critical appraisal of their value and limitations. Reprod. Dom. Anim. 47, 21-26.

Rosegrant, M.W., Cai, X. \& Cline, S.A., 2002. Global water outlook to 2025, averting crisis. A 2025 vision for food, agriculture, and environment initiative. Washington DC. IFPRI and IWMI.

Shourbagy, S.H., Spikings, E.C., Freitas, M.A. \& St John, J.C., 2006. Mitochondria directly influence fertilization outcome in the pig. Reprod. 131, 233-245.

Su, J., Wang, Y., Li, R., Peng, H., Hua, S., Li, Q., Quan, F., Guo, Z. \& Zhang, Y., 2012. Oocytes selected using BCB staining enhance nuclear reprogramming and the in vivo development of SCNT. Plos One.doi: 10.1371/journal.pone 0036181.

Wang, L., Lin, J., Huang, J., Wang, J., Zhao, Y. \& Chen, T., 2012. Selection of ovine oocytes by brilliant cresyl blue staining. J. Biomed. Biotechnol. 7, 1155.

Yamashita, Y., Okamoto, M., Kawashima, I., Okazaki, T., Nishimura, R., Gunji, Y., Hishinuma, M. \& Shimada, M., 2011. Positive feedback loop between prostaglandin $E_{2}$ and EGF-like factors is essential for sustainable activation of $\mathrm{MAPK}_{3} /_{1}$ in cumulus cells during in vitro maturation of porcine cumulus oocyte complexes. Biol. Reprod. 6, 105-114.

Younis, A.I., Zuelke, K.A., Harper, K.M, Oliveira, M.A.L. \& Brackett, B.G., 1991. In vitro fertilization of goat oocytes. Biol. Reprod. 44, 1177-1182. 